\title{
Effect of Artificial Endolymph Injection into the Cochlear Duct on Perilymph Potassium
}

\author{
Akinobu Kakigia, ${ }^{a}$ Alec N. Salt ${ }^{c}$ Taizo Takeda ${ }^{b}$ \\ ${ }^{a}$ Department of Otolaryngology, Faculty of Medicine, University of Tokyo, Tokyo, and ${ }^{b}$ Department of

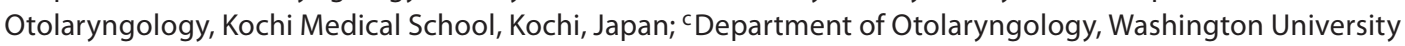 \\ School of Medicine, St. Louis, Mo., USA
}

\section{Key Words}

Endolymphatic hydrops • Artificial endolymph injection •

Perilymph potassium ion · Vertigo attack · Ménière's

disease

\begin{abstract}
Objective: To investigate the relationship between endolymphatic hydrops and perilymphatic potassium. Methods: 20 pigmented guinea pigs were used: 10 for scala vestibuli study and 10 for scala tympani study. Acute endolymphatic hydrops was produced by microinjection of an artificial endolymph into the scala media. Injections were performed in the second turn at rates up to $500 \mathrm{nl} / \mathrm{min}$ for a period of 10 $\min$. The injection volume was up to $5 \mu \mathrm{l}$. Endocochlear potential (EP) was monitored during injections. Simultaneous with the injections, the potassium concentrations in scala vestibuli $\left(\mathrm{K}_{\mathrm{SV}}\right)$ or tympani $\left(\mathrm{K}_{\mathrm{ST}}\right)$ perilymph were measured with ion-sensitive double-barreled microelectrodes sealed into in the scalae in the 3rd turn with cyanoacrylate glue. Results: For endolymphatic injections of $\leq 3 \mu \mathrm{l}$, perilymphatic $\mathrm{K}_{\mathrm{SV}}$ and $\mathrm{K}_{\mathrm{ST}}$ changes were generally small. With larger volume injections, substantial increases in both $\mathrm{K}_{\mathrm{ST}}$ and $\mathrm{K}_{\mathrm{SV}}$ were observed, with larger increases observed in $\mathrm{K}_{\mathrm{SV}}$ compared to $\mathrm{K}_{\mathrm{ST}}$. Conclusion: An increase of perilymph potassium ion concentration is associated with endolymphatic hy-
\end{abstract}

drops and the perilymphatic increase could contribute to the inner ear dysfunction of patients with Ménière's disease. Although mild hydrops may not cause perilymphatic changes, extended hydrops may increase perilymphatic $\mathrm{K}$ which could contribute to vertigo and/or hearing loss during the attack.

Copyright $\odot 2010$ S. Karger AG, Basel

\section{Introduction}

The pathological feature of Ménière's disease is endolymphatic hydrops. However, the causes of symptoms during Ménière's attacks remain unclear. Although there is some evidence that the Ménière's attack may be mechanical in origin [1], one hypothesis is that endolymphatic hydrops causes a perilymphatic potassium increase and the potassium has a toxic effect on the eighth nerve $[2,3]$. The results from temporal bone histopathology of Ménière's disease that include the rupture of the Reissner's membrane support this hypothesis. If it is the case, high $\mathrm{K}^{+}$of endolymph should leak into the scala vestibuli. The higher $\mathrm{K}^{+}$in scala vestibuli could propagate into scala tympani through the spiral ligament and, in apical regions, through the helicotrema. However, the cause of $\mathrm{K}^{+}$leakage from the endolymph could occur not

\section{KARGER}

Fax +4161306 1234

E-Mail karger@karger.ch

www.karger.com
(C) 2010 S. Karger AG, Basel

$0301-1569 / 09 / 0717-0016 \$ 26.00 / 0$

Accessible online at:

www.karger.com/orl
Akinobu Kakigi, $\mathrm{MD}, \mathrm{PhD}$

Department of Otolaryngology, Faculty of Medicine, University of Tokyo

7-3-1 Hongo, Bunkyo-ku, Tokyo 113-8655 (Japan)

Tel. +81 35800 8665, Fax +81338149486

E-Mail kakigi-tky@umin.ac.jp 
only from a rupture of the Reissner's membrane but also from a permeability change of the cochlear duct without rupture, suggested by observations that Reissner's membrane ruptures are not observed in all temporal bones following attacks. The purpose of this study was to investigate the relationship between endolymphatic hydrops and perilymphatic potassium under conditions without Reissner's membrane rupture.

\section{Materials and Methods}

Twenty pigmented guinea pigs were used: 10 for scala vestibuli study and 10 for scala tympani study. The animals were deeply anesthetized with xylazine hydrochloride $2.4 \mathrm{mg} / \mathrm{kg}$ i.m. and ketamine hydrochloride $15 \mathrm{mg} / \mathrm{kg}$ i.m. The temporal bulla was opened and the cochlea was exposed by a ventral approach. An acute endolymphatic hydrops was produced by microinjection of an artificial endolymph into the scala media. Injections were performed in the second turn at rates up to $500 \mathrm{nl} / \mathrm{min}$ for period of $10 \mathrm{~min}$. The injection volume was up to $5 \mu \mathrm{l}$. The composition of artificial endolymph was (in $\mathrm{mM}$ ) $\mathrm{KCl} 140$ and $\mathrm{KHCO}_{3} 25$ (295300 mosm). Endocochlear potential (EP) was monitored during injections. Simultaneously, the potassium concentrations in scala vestibuli $\left(\mathrm{K}_{\mathrm{SV}}\right)$ or tympani $\left(\mathrm{K}_{\mathrm{ST}}\right)$ perilymph were measured with ion-sensitive double-barreled microelectrodes sealed into the $3 \mathrm{rd}$ turn with cyanoacrylate adhesive.

\section{Results}

For endolymphatic injections of $\leq 3 \mu$, perilymphatic $\mathrm{K}_{\mathrm{SV}}$ and $\mathrm{K}_{\mathrm{ST}}$ changes were generally small. Interestingly, $\mathrm{K}_{\mathrm{ST}}$ changes were negative with a $<0.8-\mu$ l injection. With larger volume injections, substantial increases in both $\mathrm{K}_{\mathrm{ST}}$ and $\mathrm{K}_{\mathrm{SV}}$ were observed, with larger increases observed in $\mathrm{K}_{\mathrm{SV}}$ compared to $\mathrm{K}_{\mathrm{ST}}$ (fig. 1). Figure 2 shows the $\mathrm{K}_{\mathrm{ST}}$ and $\mathrm{EP}$ change with a $0.7-\mu \mathrm{l}$ injection. $\mathrm{K}_{\mathrm{ST}}$ decreased $0.34 \mathrm{mM}$ after injection, and $\mathrm{EP}$ increased $1.8 \mathrm{mV}$ after injection.

\section{Discussion}

In this study, we investigated the relationship between endolymphatic hydrops and perilymphatic potassium. With a smaller volume of endolymphatic injections, perilymphatic $\mathrm{K}_{\mathrm{SV}}$ and $\mathrm{K}_{\mathrm{ST}}$ changes were generally small. Such a small volume injection would produce only mild endolymphatic hydrops with an increase of the EP [4]. Since mild hydrops has little influence on the perilymphatic potassium concentration, this would be an unlike-

Effect of Acute Endolymphatic Hydrops on Perilymph $\mathrm{K}^{+}$

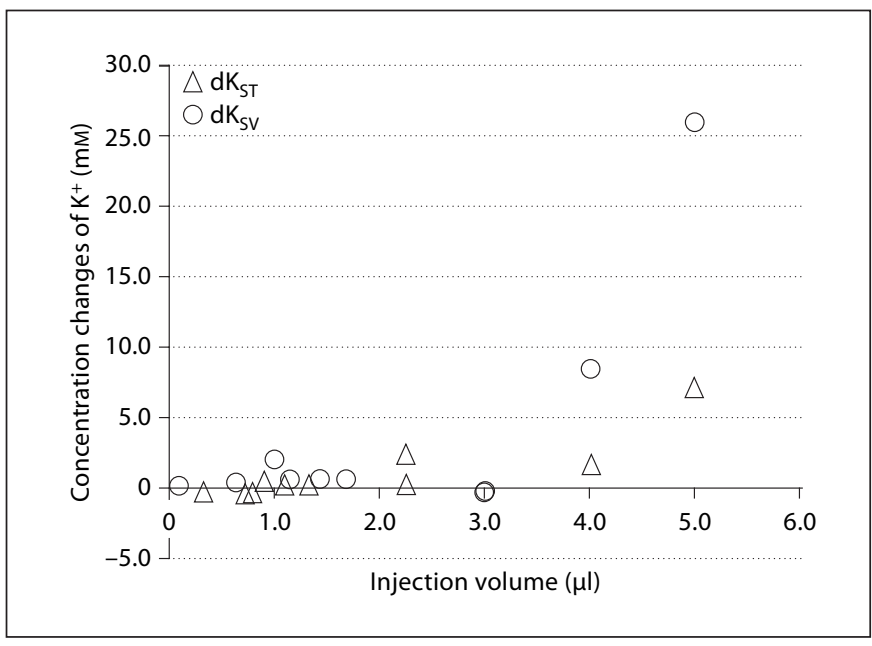

Fig. 1. Perilymph $\mathrm{K}^{+}$changes as a function of volume injected into the endolymphatic space. For $\leq 3 \mu \mathrm{l}$, perilymphatic $\mathrm{K}_{\mathrm{SV}}$ and $\mathrm{K}_{\mathrm{ST}}$ changes were generally small. Interestingly, $\mathrm{K}_{\mathrm{ST}}$ changes were negative with a $<0.8-\mu \mathrm{l}$ injection. With larger-volume injections, substantial increases in both $\mathrm{K}_{\mathrm{ST}}$ and $\mathrm{K}_{\mathrm{SV}}$ were observed. $\mathrm{dK}_{\mathrm{ST}}=$ $\mathrm{K}^{+}$change in scala tympani; $\mathrm{dK}_{\mathrm{SV}}=\mathrm{K}^{+}$change in scala vestibuli.

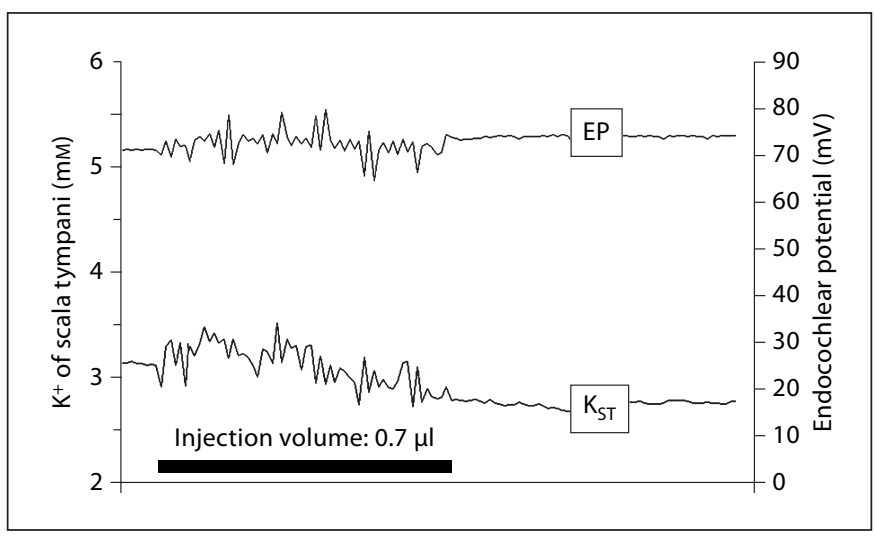

Fig. 2. $\mathrm{K}_{\mathrm{ST}}$ and $\mathrm{EP}$ changes with a $0.7-\mu$ injection. $\mathrm{K}_{\mathrm{ST}}$ decreased $0.34 \mathrm{mM}$ after injection. EP increased $1.8 \mathrm{mV}$ after injection. $\mathrm{EP}=$ Endocochlear potential; $\mathrm{K}_{\mathrm{ST}}=$ potassium concentrations in scala tympani perilymph. Thick bar $=$ artificial endolymph injection for a period of $10 \mathrm{~min}$.

ly source of any dysfunction associated with mild hydrops. Interestingly, $\mathrm{K}_{\mathrm{ST}}$ changes were negative with $<0.8$ $\mu l$ injection. This decrease of $\mathrm{K}^{+}$may be caused by a displacement of the basilar membrane. When the basilar membrane shifts toward scala tympani, the transducer channels will close and the potassium current toward scala tympani will decrease. These may be the mechanisms of $\mathrm{K}_{\mathrm{ST}}$ decrease with a small-volume injection. 
With larger-volume injections, substantial increases in both $\mathrm{K}_{\mathrm{ST}}$ and $\mathrm{K}_{\mathrm{SV}}$ were observed, with larger increases observed in $\mathrm{K}_{\mathrm{SV}}$ compared to $\mathrm{K}_{\mathrm{ST}}$. These results suggest that substantial hydrops, as is often present in Ménière's disease, could result in increased perilymphatic potassium concentration, which could contribute to auditory and vestibular dysfunction. Salt and Ohyama [5] reported that with acute manipulations of perilymph $\mathrm{K}^{+}$there was a rapid clearance of $\mathrm{K}^{+}$from the perilymph. This study also showed that $\mathrm{K}^{+}$clearance from scala tympani was faster than that from scala vestibuli. The smaller potassium change observed in scala tympani in the present study is consistent with a faster rate of potassium clearance from that scala. These results show that an increase of perilymph potassium ion concentration is associated with endolymphatic hydrops and the perilymphatic increase could contribute to the inner ear dysfunction of patients with Ménière's disease.

\section{Disclosure Statement}

The authors are not aware of any conflict of interest or similar issue that may be relevant to the present work.
References
1 McNeill C, Cohen MA, Gibson WP: Changes in audiometric thresholds before, during and after attacks of vertigo associated with Ménière's syndrome. Acta Otolaryngol 2009; 4:1-4.

2 Lawrence ML, McCabe BF: Inner ear mechanics and deafness: special consideration of Ménière's syndrome. JAMA 1959;171: 1927-1932.
3 Schuknecht H: The pathology of Ménière's disease; in Vosteen KH, et al (eds): Ménière's Disease. Pathogenesis, Diagnosis and Treatment. Stuttgart, Thieme, 1981, pp 10-15.

$\checkmark 4$ Kakigi A, Takeda T: Effect of artificial endolymph injection into the cochlear duct on the endocochlear potential. Hear Res 1998;116: 113-118.

5 Salt AN, Ohyama K: Accumulation of potassium in scala vestibuli perilymph of the mammalian cochlea. Ann Otol Rhinol Laryngol 1993; 102:64-70. 